\title{
Processing and analysis of aeromagnetic data - Passa Quatro and Itatiaia Alkaline Complexes (RJ, SP and MG - Southeast of Brazil)
}

Fabio Vladimir Santos ${ }^{* 1}$ and Saulo S. Martins ${ }^{1,2},{ }^{1}$ PPGMEG-UFRRJ, ${ }^{2}$ Graduate Program in Geology - UFRRJ

\section{Copyright 2021, SBGf - Sociedade Brasileira de Geofísica}

This paper was prepared for presentation during the $17^{\text {th }}$ International Congress of the Brazilian Geophysical Society held in Rio de Janeiro, Brazil, 16-19 August 2021.

Contents of this paper were reviewed by the Technical Committee of the $17^{\text {th }}$ International Congress of the Brazilian Geophysical Society and do not necessarily represent any position of the SBGf, its officers or members. Electronic reproduction or storage of any part of this paper for commercial purposes without the written consent of the Brazilian Geophysical Society is prohibited.

\begin{abstract}
The Passa Quatro Alkaline Complex (CAPQ) in general represents the biggest felsic plutonic rock complex of the Mesozoic-Cenozoic age. It's a batholitic complex associated with the hypabyssal rocks, as dikes and spills. The CAPQ is located between Minas Gerais, Rio de Janeiro, and São Paulo state border, it's embedded in the gneisses and other metamorphic rocks of Brasiliana-Pan Africana age of Ribeira mobile Belt. The alkaline rocks outcropping of CAPQ has an elliptical-rounded shape exposing approximately $150 \mathrm{~km}^{2}$ of rocks with a general $\mathrm{E}-\mathrm{W}$ strike direction. The emplacement of the plutonic rocks is associated with the reactivation of basement structures and failures related to the rupture of the Gondwana Paleocontinent. The alkaline bodies associated with the same evolutive process that CAPQ has its genesis linked to the partial melting of mantle mafic rocks and correlated to the fractional crystallization. Magnetometric data can be a great tool to test geodynamic models for the complex, considering the absence of evidence corresponding to the parental or primary mantle magma. The database of the Companhia Brasileira de Recursos Minerais (CPRM) represents a reliable and quality source of aeromagnetometric data and Oasis Montaj is the software scattered in the academic and professional networks to process the CPRM database. Filters associated with mathematical and geophysical algorithms were used to enhance analytical signals, delimit and analyze the CAPQ magnetic anomaly. Throughout the research, we came across the Itatiaia Alkaline Complex (ITA) that will be treated along with this work and whose initial scope was not our focus.
\end{abstract}

\section{Introduction}

The CAPQ is located on the triple border of the Minas Gerais, Rio de Janeiro, and São Paulo states (Figure 01) and corresponds to a batholithic rocky body at the large in a series of alkaline felsic rocks of Mesozoic-Cenozoic age - syenites, nepheline syenites, syenites, foliates, nepheline microsienites, and porphyroid tinguaites, in addition, the occurrence of phonolytic dykes and hypoabissal rocks formations (Ribeiro Filho, 1963; Brotzu et al., 1992). The CAPQ emerges to the west of the CAl, has an elliptical-rounded shape, with exposure of approximately $150 \mathrm{~km}^{2}$ of alkaline rocks, embedded in the gneisses of the Ribeira Orogeny (Chiesi, 2004). CAPQ is inserted in the Cabo Frio - Poços de Caldas magmatic-structural alignment, which comprises about 30 intrusive centers, has a general E-W strike direction from of Brasilian Pan- African structures reactivation of the basement and ongoing failures related to Gondwana rupture (Almeida, 1983). Chiesi, 2004 and Brotzu et al., 1992 described the CAPQ as a polyphasic tectonomagmatic feature composed of intrusive and unsaturated felsic rocks represented by solid and laminated syenite nepheline, micro syenite nepheline, subvolcanic rocks, such as phonolite and trachyte dikes, and alkaline polymythic breccias.

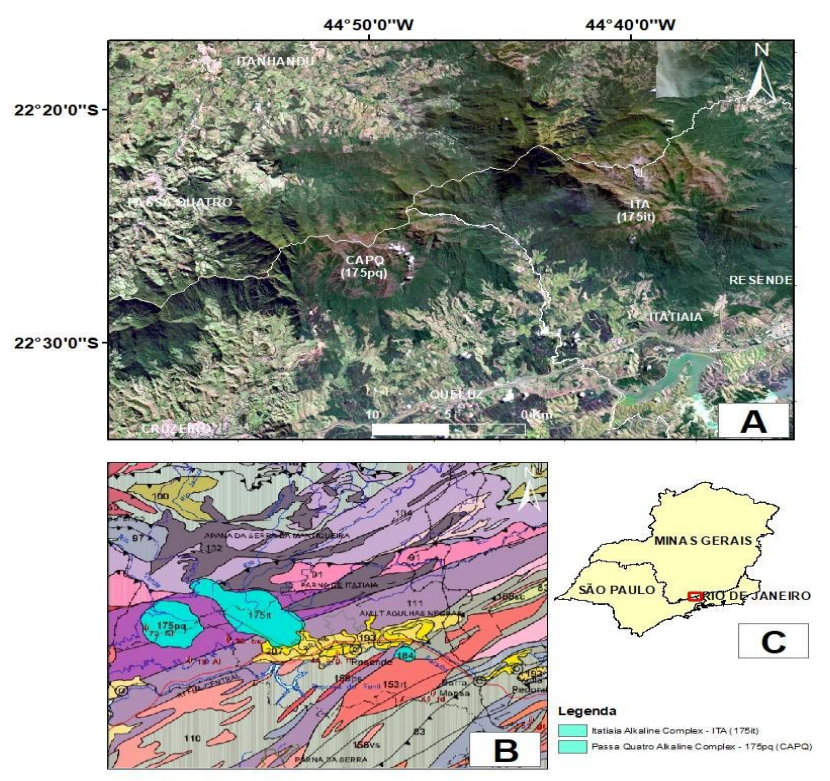

Figure 01: Location of the work area. A - Alkaline Complexes of Itatiaia and Passa Quatro between the triple border of Rio de Janeiro, São Paulo and the Minas Gerai states; B - CPRM SF23 Rio de Janeiro geological 1:1.000.000 schematic representation of Itatiaia and Passa Quatro intrusive complexes in metamorphic basement rocks and $C$ - Regional map location the red square indicates the fieldwork. 
Invariably the CAPQ research is focused on geochemical or geochronological issues or associated with the Poços de Caldas-Cabo-Frio alignment evolution. Lopes et. al, (2015) based on petrological studies including mapping detail, conventional petrography, geochemistry, and geochronology aiming at the genesis and evolution of the Passa Quatro Alkaline Complex, in preliminary studies, pointed to the magmatic origin of the plutonic lithotypes of the massif, however without field occurrences of parental representative rocks. The main evolution process of felsic alkaline lithotypes would be related to fractional crystallization. In recent studies, the authors point that plutonic CAPQ primary magma would be of mantle source, from the crust base interface, which evolved after the amalgamation of contiguous magmatic chambers at crustal levels. The Total Anomalous Field of the Passa Quatro area is associated in-depth with the adjacent alkaline complexes of Itatiaia (ITA). The ITA presents an anomaly that at first appears to be inseparable from that generated by the CAPQ, however, the literature points out different alkaline bodies about the petrogenetic viewpoint. The ITA is composed of lithotypes saturated in silica and Passa Quatro unsaturated and the ages of the complexes show a close range, can be the complexes represent a single root and represent two pulses of the same parental magma.

The processing and modeling of magnetometric data can be used as a tool to test geodynamic models, considering no mafic outcrops representing the less evolved among the CAPQ lithotypes correlated with the primary or parental magma and evolved until the phaneritic plutonic lithotypes. Another path to follow in this research is related to the analysis of the intrinsic geological relationship between CAPQ and ITA in depth.

\section{Material and Method}

Magnetic data is one of the frameworks for geophysical potential methods in the geological investigation. Alkaline rocks, rich in minerals magnetically susceptible, represents excellent objects for an Anomalous Magnetic Field study.

The input database was compiled from the CPRM Serviço Geológico do Brasil (1105_MAGLINE.XYZ). The data were processed in the Oasis Montaj software, generating, together, a database containing a spreadsheet with the values of the acquired magnetic anomalies and all field data collected by CPRM. After the steps of importing data and configuring coordinates parameters, we use geophysical and mathematical filters that represent algorithms derived in the Total Anomalous Field using the Fast Fourier Transformed (FFT), associated with the MAGMAP Filtering tool from Oasis Montaj.

The Oasis Montaj ownership by Geosoft presents a series of filters and digital tools to process and determine geophysical data, including magnetometric data. Spatial filters are applied in the FFT field and make it possible to smooth and filter the anomaly data in the frequency field, highlighting features and contours, supporting surveys, and geological field maps with information about the shape, contacts, transition, or depth of magnetically susceptible lithotypes. The analysis is possible with mathematical equations applications. The space domain it's converted via FFT or Inverse Fourier Transform, according to the better visualization or emphasis of a body, structure, or feature desirable to view. Oasis Montaj uses shorter wavelength enhancement filters, such as high-pass, vertical and horizontal derivatives to highlight the geological characteristics and filters to smooth, accentuating the characteristics of the longest wavelength, removing or attenuating the characteristics of wavelengths.

\section{Processing data}

Considering some filters features and the results observed three filters and the combination of two others were chosen to present the results: Analytical Signal (ASA), Horizontal Total Gradient $(\mathrm{GHT})$, Tilt Derivative (ISA), ASA + GHT and ASA + ISA.

ASA: Used to derive the functions in axis $x, y, z$. Has applied for the visualization and mapping of the edges and contour of the anomalous body, that is, it highlights its geometry. The signal amplitude is highlighted at the edges by the displacement of the maximum values, considering the combination of the horizontal and vertical gradients, highlighting the strongest anomaly in one of its poles, centering the source, without considering, however, the inclination and declination parameters. Considering that we do not have the actual values of inclination and declination, the ASA filter is useful for transforming the total field data into data reduced to a pole.

GHT: Used to derive the analytical signal in the horizontal axis $(x, y)$. Considering the changes in the properties of magnetic susceptibility between the bodies enhances the contacts between these and the edges of the bodies. The greater the difference in susceptibility between lithotypes, the more evident the contours. It has the characteristic of highlighting high frequencies, positioning the peaks at the edges and the pits at the central part of the anomaly. Its performance is marked on shallow structures and decreases as the depth increases.

ISA: Its application correlates the vertical derivative with the GHT. The ratio between those derived by the tangent angle highlights small and large wave amplitudes, highlighting shallow and deep linear structures. The ISA filter balances and normalizes the anomaly, emphasizing the peaks in the center, weakening towards the edges. Like ASA filter, the derivative of the functions on the three axes allows the body to be viewed in its monopolar form, centering the source and its use to delimit borders is not applicable.

The association between filters to enhance physical characteristics is one of the possibilities that can be used in the Oasis Montaj software.

ASA + GHT: Considering the feature of each of the filters, as a result we hope to further highlight the anomaly 
geometry through a better delineation of the body contour, since the ASA filter allows to derive the anomaly in its three axes and make it monopolar and that the GHT filter better highlights the edges of the body.

ASA + ISA: This association is expected to eliminate the edges of anomalies and to highlight deeper structures.

The processing highlights features that are important for the analysis of the geometry and continuity of the intrusive bodies of $C A P Q$, in addition to showing in more detail the structural lineaments of the region and possible integration with the intrusive lithotypes of Itatiaia. All the results of the processing can be seen in Figure 02 .

\section{Results}

Figure $2 \mathrm{~A}$ shows the raw data provided by CPRM. The $X Y Z$ file was removed from the database and corresponds to the CAPQ-ITA Total Anomalous Magnetic Field, plotted the spatial domain, after the basic processing performed by CPRM, removing the IGRF field. In this picture, it is possible to observe that the CAPQ magnetic field has an interrelation with the anomaly of the ITA, showing a biggest dipole that, initially, seems inseparable representing a single anomaly. The CAPQ-ITA dipole is surrounded by other linear anomalies, arranged in the NE / SW direction, possibly related to the Ribeira metamorphic terrain, and the smallest circular dipole anomaly, located SE, related to the alkaline intrusion of Morro Redondo. Passa Quatro and Itatiaia alkaline complex represent lithotypes dissociated from the geochemical and geochronological viewpoints and this biggest anomaly must dissociate in deep.

Figure 2B corresponds to the ASA applied directly in the Total Magnetic Anomalous Field. From ASA the dipolar anomaly became a monopole and expressed the most intense pole of the body. ASA filter has a problem related to high frequencies and noises. This filter amplifies the noise and high frequencies and as result generates spurious rounded signs. After applying the ASA, it's possible to highlight the contours of the Passa Quatro and Itatiaia plutons in-depth and the irregular borders of the intrusions suggest different pulses or phases of crystallization. The dipolar anomaly is shown in Figure $2 \mathrm{~A}$, now presents a uniform gradation of the most intense phase, in a magenta tone. The elongated semicircular shape $\mathrm{E}-\mathrm{W}$, characteristic of the rock outcrops in CAPQ is more irregular in depth, suggesting that the pluton root is not uniform. The characteristic contour of the ITA, stretched from SE to NW, still be visualized, but not so homogeneously, emphasizing, especially in its central portion, the contour of an anomaly that seems deepest. Structures aligned in the NE-SW direction, well characterized in the total anomalous field data, including the Brasilian crustal stretching, are firmly marked in depth. The filtered data also show high-frequency noise in the North-South direction, especially in the upper corner of the NW of the anomaly of the Alkaline Complexes of Passa Quatro and Itatiaia.
Figure $2 \mathrm{C}$ shows the application of the GHT filter over the Total Anomalous Magnetic Field. The dipolar anomaly is homogenized and presents a similar result when applied to the ASA filter on the Anomalous Magnetic Data Field. Considering the characteristics of this algorithm, it's possible to observe a decrease in the noise and high-frequency signal in comparison with ASA. The contours were slightly accentuated and some individualized parts in ASA are smooth.

A filter association was applied to generate Figure 2D. The ASA filter was applied over the GHT filter, shown in Figure $2 \mathrm{C}$. As a result, we obtained an increase in low and high-frequency noise. This association was not positive for the delimitation of the CAPQ-ITA. The N-S / E-W noises stand out concerning the ASA and GHT filters when applied separately. We can see the outline of the anomalies; however, the lower energy phases appear distributed irregularly. Regional structures show how the data is masked. The NE-SW lineaments typical of Brasilian Pan- African basement, observed in the previous figures, and the subordinate and more anisotropic stretchings, keep some linearity but are filled with noise in the form of small rounded dots.

The ISA filter, Figure 2E, was applied over the Anomalous Magnetic Total Field. The Tilt Derivative algorithm filtered the raw data equally. The dipole phases showed the regional lineaments in the NE-SW direction. The anomaly related to the Alkaline Complexes (CAPQ-CAI) has practically disappeared, except for a prominent sign in the northern portion of the area, aligned in the E-W direction, following the preferential attitude of the Passa Quatro fitting, as well as the NW-SE tracking that was used as a conduit for the intrusion of the rocks of Itatiaia. The stretch features the Mantiqueira Tectonic Province, where the $C A P Q$ is located. An anomaly points out to a structure with regional proportions that has not been previously observed to SSE of the CAPQ-ITA.

The ASA filter was applied on the ISA filter, Figure 2E, generating Figure 2F. This association highlights the deep regional structures in the NE-SW direction, especially in the southern segment of the area. The noise or interference caused to the WNW area blocks any possibility of visualizing the structure in that segment. The lineaments are highlighted with this filter association. In the border area, we can observe the morphometric delineation of the anomaly denoting an undissociated rounded body with the preferential strike direction E-W, which covers the CAPQ-ITA. The lineaments that were prominently highlighted in the area of intrusions seem to indicate the reactivation or compartmentalization of E-W at some stage of placing the bodies.

\section{Conclusions}

The CAPQ-ITA magnetic potential data processing and analysis showed a good tool as an auxiliary method to petrologic issues if necessary. The project begins with a pragmatic vision to look for a possibility or not of a geodynamic model proposal associated with a possible magmatic parental source to the CAPQ. However, the 
PROCESSING AND ANALYSIS OF AEROMAGNETIC DATA OF PASSA QUATRO AND ITATIAIA

filters and the possibilities during the research follow to present results and previews.

Regionally, we observed that the filters highlighted the Brazilian structures arranged in the preferential NE-SW direction. The response verified with the application of the ISA filter and this one combined with the ASA filter, marked well the shallow and deep regional Brasilian Pan African lineaments, and bandings, faults, and deformations occurred in the Gondwana Paleocontinent amalgamation. The filters showed an E-W alignment through the outcrop area of CAPQ-ITA and which may indicate a deep structure oblique to those of regional activity and in agreement with the structure that housed the magmatism of CAPQ-ITA.

The GHT and ASA filters enhance the contour of the edges of the analytical signal of the CAPQ-ITA. The internal fragmentation of the alkaline complex and the heterogeneous character of the intrusions, showing that their deep roots are irregular. In this sense, it's observed and inferred about the possibility of reactivating faults, different intensively of magmatic pulses, cooling processes or neotectonic activities, e.g, or different hypoabissals rocks intrusions inside the plutons.

Is not possible to dissociate the anomalous field from the $C A P Q$ and ITA, suggesting strongly the one roof in-depth. It's a hard petrologic question regarding geochemistry and geochronology. However, this occurrence can only show the interaction between the anomalous fields that would be very close and would have a direct influence on each other to the point of generating a major anomaly.

The Passa Quatro and Itatiaia Alkaline Complexes had a strong remaining magnetic anomaly whose indissociable response can support new geological proposals. The processing and analysis open possibilities for interpreting data, concepts, and models regarding the CAPQ-ITA emplacement.

- The Total Magnetic Anomalous Field of Passa Quatro and Itatiaia points out to an undissociated.

Are CAPQ and ITA only one complex CAPQ-ITA?

- The preferred emplacement directions for CAPQ and ITA complexes are clear and reflect in-depth and surface. However, deepest anisotropic structures internally into the alkaline bodies indicate possible fails reactivation, magmatic freeze processes, intern magmatic pulses, dykes intrusions, etc. Regional lineaments, including continental suture zones, are well marked on the anomalous body and a deep alignment in the E-W direction extends to the northern portion of the area.

Can the field evidence be associated with some structural or petrographic event described?

Is possible deepest E-W zones under the CAPQ-ITA area where $72-64 \mathrm{Ma}$ the original parental magma of CAPQ-ITA was housed and flowed to give rise to the lithotypes of the complexes?

\section{Acknowledgments}

The authors would like to thank CPRM for the data given. they would like to thanks SEEQUENT for a technical assistant. Fabio V. Santos received a PETROBRAS scholarship. This research was fully supported by PETROBRAS (project number: 2017/00353-1).

\section{References}

Almeida, F. F. M. de, 1983. Relações tectônicas das rochas alcalinas mesozóicas da região meridional da plataforma Sul-Americana. Revista Brasileira de Geociências, 13(3), p. 139-158, 1983.

Almeida, F. F. M. de; Carneiro C. D.R, . Magmatic occurrences of post-Permian age of the South American Platform. Proceedings Bol. IG-USP, Sér.Cient, 20: 71-85,1989.

Brito Neves B. B.; Cordani U. G. Tectonic evolution of South America during Late Proterozoic. Precambrian Research, 53, p. 23-40. 1991.

Brotzu, P.; Gomes, C. B.; Melluso, L.; Morbidelli, L.; Morra V.; Ruberti, E. Petrogenesis of coexisting SiO2-undersaturated to SiO2-oversaturated felsic igneous rocks: The alkaline complex of Itatiaia, southeastern Brazil. Lithos 40, p. 133-156. 1997.

Brotzu, P.; Barbieri, M; Beccaluva, L; Garbarino, C.; Gomes, C. B.; Macciotta, G.; Melluso, L.; Morbidelli, L.; Ruberti, E.; SIGOLO, J. B.; Traversa, G. Petrology and geochemistry of the Passa Quatro alkaline complex, Southeastern Brazil. Journal of South American Earth Science, 6(4), p. 237-252. 1992.

Chiessi, Cristiano Mazur. Tectônica cenozoica do maciço alcalino de Passa Quatro (SP-MG-RJ). 2004. $129 \mathrm{f}$. Dissertação (Mestrado) - Programa de Pós-Graduação em Geologia Sedimentar da Universidade de São Paulo, 2004.

Ribeiro Filho, Evaristo. Maciços Alcalinos do Itatiaia e de Passa Quatro (Sudeste do Brasil): Contribuição à Geologia e Petrologia. 1963. 90 f. Tese (Doutorado) Faculdade de Filosofia, Ciências e Letras da Universidade de São Paulo, 1963.

Heilbron, M., Pedrosa-Soares, A. C., Campos Neto, M. da C., Silva, L. C. da, Trouw, R. A. J., \& Janasi, V. de A. (2004). Província Mantiqueira. In Geologia do continente sul-americano: evolução da obra de Fernando Flávio Marques de Almeida. São Paulo: Beca.

Lopes, J. C.; Valente, S. C.; Geraldes, M. C. 2015. Evidências petrográficas para possível cogeneticidade entre litotipos félsicos com diferentes graus de saturação em sílica no Complexo Alcalino Passa Quatro, Província da Serra do Mar. In: VI Simpósio de Vulcanismo e Ambientes Associados. São Paulo - USP. Boletim de Resumos, 2015. p. 84-84. 


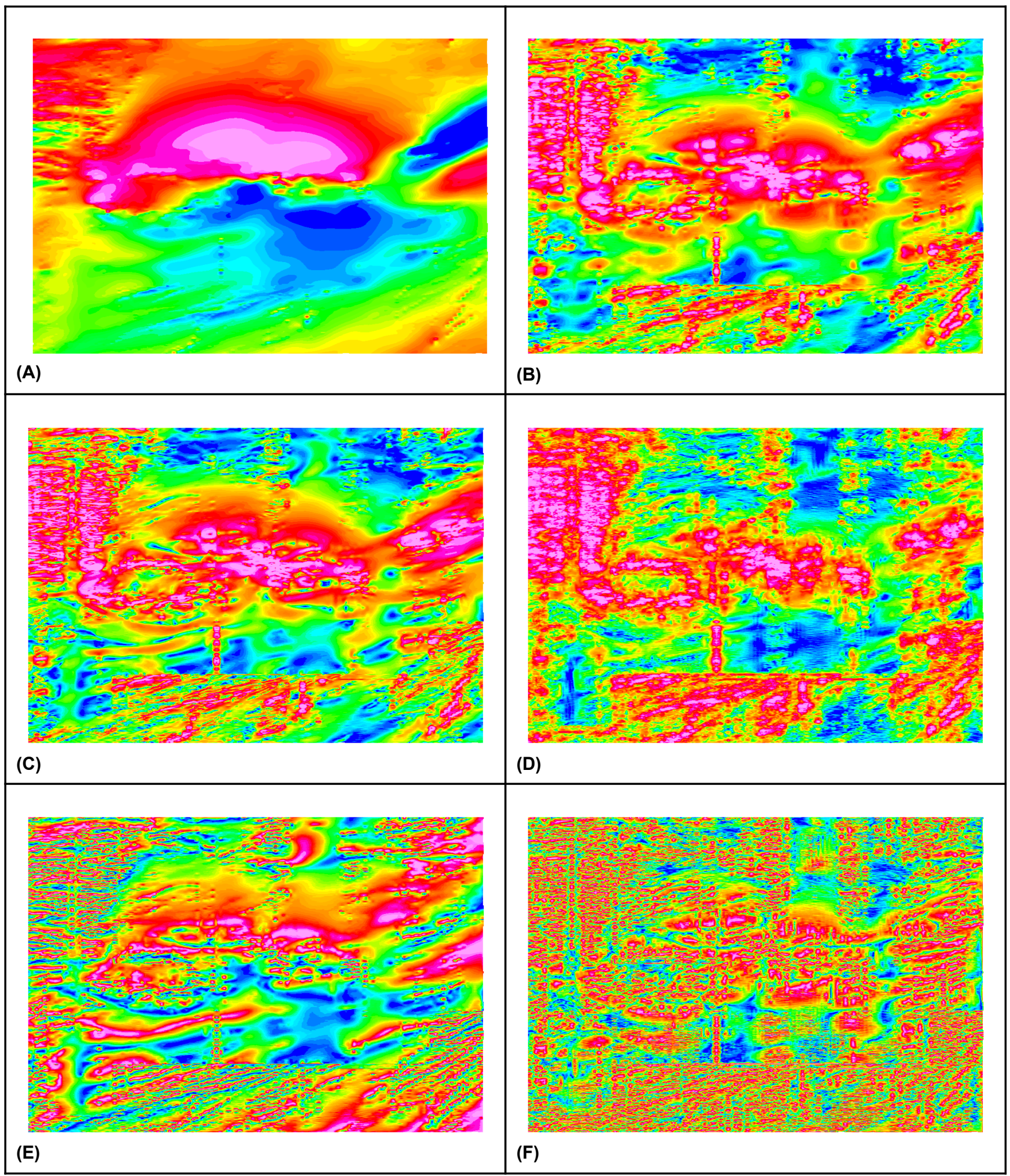

Figure 02: Aeromagnetic data and the processing. (A) raw data removed IGRF, (B) ASA filter applied in Total Magnetic Anomalous Field, (C) GHT filter applied in Total Anomalous Magnetic Field, (D) The ASA + GHT filter applied in Total Anomalous Magnetic Field, (E) The ISA filter applied in Anomalous Magnetic Total Field and (F) The ASA + ISA filter applied in Total Anomalous Magnetic Field. 